\title{
ASPECTOS CONTROVERSOS SOBRE A PROPRIEDADE INTELECTUAL NA ERA DIGITAL
}

\section{CONTROVERSIAL ASPECTS ON INTELLECTUAL PROPERTY IN THE DIGITAL AGE}

\section{ASPECTS CONTROVERSES DE LA PROPRIÉTÉ INTELLECTUELLE À L'ÈRE NUMÉRIQUE}

Patrícia Verônica Nunes Carvalho Sobral de Souza ${ }^{1}$

\author{
RECEBIBO 29/05/2019 \\ APROVADO 30/06/2019 \\ PUBLICADO 01/07/2019 \\ Editor Responsável: Carla Caldas \\ Método de Avaliação: Double Blind Review \\ E-ISSN: $2316-8080$ \\ DOI:10.16928
}

\section{Resumo}

A Propriedade Intelectual atua como esfera do conhecimento que se consubstancia na materialização da garantia da criação humana, por meio da atribuição de direitos de apropriação pelo homem sobre as suas criações, obras ou produções. A Organização Mundial de Propriedade Intelectual (OMPI) é uma organização intergovernamental e é unicamente destinada e especializada para lidar com assuntos inerentes a regulamentação e proteção dos direitos autorais. Através deste trabalho pretende-se alcançar quais as vantagens e dificuldades encontradas nas leis vigentes, a natureza, gêneros e espécies de criações intelectuais que são passíveis de proteção e os respectivos direitos de Propriedade Intelectual. Ainda, será abordada a polêmica sobre o direito à propriedade face a inteligência artificial. Para tanto, a partir da metodologia exploratória de caráter descritivo e bibliografia especializada sobre o tema, observa-se inovações patenteadas que impulsionam os processos de desenvolvimento e fonte de renda dos países. Os direitos autorais, portanto, podem ser compreendidos como um instituto revestido por uma dualidade de interesses. Interesses privados, baseados no exercício da liberdade de expressão e no anseio do autor em ter recompensa em decorrência de sua criação intelectual, bem como, de outro lado, de interesses que beneficiam o crescimento do patrimônio cultural de toda a sociedade, através do uso de obras e tecnologias decorrentes da inteligência artificial que se torna cada vez mais necessária e utilizada globalmente.

Palavras-Chave: Direitos Autorais. Inteligência Artificial. Patente. Propriedade Industrial. Propriedade Intelectual.

\section{Abstract}

\footnotetext{
${ }^{1}$ Pós-doutoranda e Doutora em Direito Público pela Universidade Federal de Bahia (UFBA). Doutora em Educação e Mestra em Direito pela Universidade Federal de Sergipe (UFS). Especialista em Direito do Estado e Especialista em Direito Municipal (UNIDERP). Especialista em Direito Civil e Processo Civil pela Universidade Tiradentes (UNIT). Especialista em Auditoria Contábil pela Universidade Federal de Sergipe (UFS). Professora de Graduação e Pós-graduação da Universidade Tiradentes (UNIT). Líder do grupo de pesquisa Direito Público, Educação Jurídica e Direitos Humanos. Diretora Técnica do Tribunal de Contas do Estado de Sergipe. E-mail: patncss@gmail.com. Orcid: http://orcid.org/0000-0002-3725-6339. Link currículo lattes http://lattes.cnpq.br/7502386530836336.

PIDCC, Aracaju/Se, Ano VIII, Volume 13 no 02, p.048 a 068 Jul/2019 | www.pidcc.com.br
} 
Intellectual Property acts as a sphere of knowledge that is embodied in the materialization of the guarantee of human creation, through the attribution of rights of appropriation by man on his creations, works or productions. The World Intellectual Property Organization (WIPO) is an intergovernmental organization and is solely dedicated and specialized to deal with matters pertaining to regulation and protection of copyright. Through this work we intend to reach the advantages and difficulties found in the current laws, the nature, genres and species of intellectual creations that can be protected and the respective Intellectual Property rights. Also, the controversy over the right to property against artificial intelligence will be addressed. In order to do so, based on the exploratory methodology of a descriptive character and specialized bibliography on the subject, we can observe patented innovations that drive the countries' development processes and source of income. Copyright, therefore, can be understood as an institute coated by a duality of interests. Private interests, based on the exercise of freedom of expression and the author's desire to be rewarded as a result of his intellectual creation, as well as, on the other hand, interests that benefit the growth of the cultural heritage of the whole society through the use of works and technologies derived from artificial intelligence that is increasingly needed and used globally.

Key words: Copyright. Artificial Intelligence. Patent. Industrial Property. Intellectual Property.

Résumé

La propriété intellectuelle agit comme une sphère de connaissances qui s'incarne dans la matérialisation de la garantie de la création humaine, par l'attribution de droits d'appropriation par l'homme sur ses créations, œuvres ou productions. L'Organisation Mondiale de la Propriété Intellectuelle (OMPI) est une organisation intergouvernementale exclusivement dédiée et spécialisée dans le traitement de questions relatives à la réglementation et à la protection du droit d'auteur. À travers ce travail, nous entendons atteindre les avantages et les difficultés rencontrés dans les lois en vigueur, la nature, les genres et les espèces de créations intellectuelles pouvant être protégés ainsi que les droits de propriété intellectuelle respectifs. La controverse sur le droit de propriété contre l'intelligence artificielle sera également abordée. Pour ce faire, sur la base de la méthodologie exploratoire à caractère descriptif et de la bibliographie spécialisée sur le sujet, nous pouvons observer des innovations brevetées qui orientent les processus de développement et la source de revenus des pays Le droit d'auteur peut donc être compris comme un institut revêtu d'une dualité d'intérêts. Les intérêts privés, fondés sur l'exercice de la liberté d'expression et le désir de l'auteur d'être récompensé du fait de sa création intellectuelle, ainsi que, d'autre part, des intérêts bénéfiques à la croissance du patrimoine culturel de l'ensemble de la société grâce à œuvres et technologies dérivées de l'intelligence artificielle, de plus en plus nécessaires et utilisées dans le monde entier.

Mots-clés: Droit d'auteur. Intelligence artificielle. Brevet Propriété industrielle. Propriété intellectuelle..

\section{INTRODUÇÃO}

Propriedade Intelectual é o conjunto de direitos que incidem sobre o intelecto humano. Em um mundo onde os processos de inovação baseiam-se na apropriação dos conhecimentos científicos e tecnológicos, a Proteção da Propriedade Intelectual é cada vez mais importante. O conhecimento e direito sobre a criação se torna intangível, com a ajuda de leis elaboradas com fins exclusivos de protegê-los (BARBOSA, 2017). 
A Constituição brasileira de 1988, decerto, aborda uma definição especial sobre direitos considerados como fundamentais, inserindo em seu art. $5^{\circ}$, inciso XXIX, a concessão de privilégio temporário aos autores de invenções industriais, a sua garantia, bem como à propriedade das marcas, aos nomes de empresas e outros signos distintivos, com a finalidade de proteger o interesse social, assim como o desenvolvimento tecnológico e econômico do País.

Cada país editou leis próprias que regulam o regime de propriedade intelectual em seus domínios. No Brasil, as principais leis sobre o tema são a 9.609/98 (Lei de Software) e a 9.610/98 (Lei de Direitos Autorais).

Esta última lei, a dos Direitos Autorais, busca assegurar a proteção de ideias em trabalhos produzidos e publicados ou não publicados nas áreas da literatura, teatro, música e coreografias de dança, bem como de filmes, fotografias, pinturas, esculturas e outros trabalhos visuais referentes a arte, entre eles, programas de computador (softwares), reservando para seus autores o direito exclusivo de reproduzir seus trabalhos.

A Lei do Software, por sua vez, dispõe que os programas de computador estão sujeitos à proteção de direitos autorais como obras literárias, ainda que existam em um formato, como um código de objeto, ressalvando alguns direitos morais e, ainda, que os direitos sobre o software são do empregador.

A presente reflexão tem por escopo debater os entraves existentes na propriedade intelectual, como um instrumento muito importante para o desenvolvimento do país e o efetivo atendimento ao que dispõe a Lei $n^{\circ}$ 9.610/98, diante da nova era digital.

Para tanto, utilizou-se da metodologia exploratória de caráter descritivo, que, por meio da exploração bibliográfica examina a doutrina, legislação e periódicos pertinentes ao tema levantado, buscando contextualizar e conceituar a propriedade intelectual no cenário tecnológico.

\section{CONTEXTO EVOLUTIVO DA PROPRIEDADE INTELECTUAL}

Os direitos autorais têm sua origem, segundo a doutrinadora Eliane Yachouh Abrão (2014), na Grécia Antiga, mediante a necessidade de efetuar o depósito oficial dos textos literários. A finalidade era preservar a memória escrita da civilização. À época, os textos escritos, de forma manual, eram vendidos pelos livreiros, donos do negócio, seguindo as regras da propriedade móvel comum.

PIDCC, Aracaju/Se, Ano VIII, Volume 13 no 02, p.048 a 068 Jul/2019 | www.pidcc.com.br 
Todavia, a criação intelectual só recebeu de fato uma proteção com o advento das teorias individuais e liberais da Revolução Francesa, que originaram dois sistemas, o sistema anglo-saxão de proteção à obra, e o sistema europeu de proteção à personalidade do autor.

O surgimento da efetiva tutela do direito do autor se deu com o Estatuto da rainha Ana, em 1710, na Grã-Bretanha, onde se concedeu o privilégio de reprodução, surgindo o copyright (BITTAR, 2019). No entanto, nesse momento, havia a confusão entre a obra e sua materialidade, e, com essa distinção começa a defender a imaterialidade da obra literária, originando a concepção de bens incorpóreos.

Inicialmente, surgiu o copyright, de origem anglo-saxônica que consiste no direito de cópia e é também uma das vertentes dos direitos de autor, correspondendo ao direito de exploração econômica de qualquer escrito. Só após a criação do copyright é que os autores participam nas vendas das cópias, onde estes passaram a receber royalties ou direitos patrimoniais, que são percentuais incidentes sobre os valores das vendas.

Os direitos do autor surgiram na França, país de tradição romanística. Os dois sistemas anteriormente descritos, passaram a se enfrentar em nível internacional, no pósguerra nos EUA cujas leis internas não se adequavam à Convenção Internacional de Berna para proteção de obras literárias, artísticas e científicas, convenção esta que aconteceu em setembro de 1886 e estabeleceu parâmetros essenciais até hoje, entre eles: o que é obra literária e artística; apresentou os critérios para proteção autoral; conceituou o que é obra publicitária; o autor passou a ser identificado perante os tribunais pelo seu nome aposto à obra, mesmo que seja um pseudônimo; garantiu o direito de adaptação e tradução autorizada, além daqueles sobre obras dramáticas e dramático-musicais; fixou o prazo de vigência dos direitos do autor após sua morte: 50 anos.

Em 1952, criou-se a Convenção Universal de Genebra e a Convenção Universal dos Direitos de Autor que exigiram uma formalidade mínima para que o direito do autor sobre a obra pudesse existir. O interesse da comunidade internacional, principalmente nas nações da União de Berna na Convenção de Genebra era o de viabilizar a efetiva proteção de obras estrangeiras nos Estados Unidos, país com um dos mercados consumidores mais expressivos do mundo, em especial no que concerne à indústria de bens culturais.

\subsection{Direitos da Propriedade no Brasil}


Quanto à proteção constitucional dos direitos autorais no Brasil, a primeira Constituição a garanti-los foi a da República dos Estados Unidos do Brasil de 24 de fevereiro de 1891, que previa na seção da Declaração de Direitos, a primeira disposição jurídica que definiu os direitos autorais, prevista no artigo 72 , parágrafo 26 , que continha a seguinte redação: "É garantido aos autores de obras literárias e artísticas o direito exclusivo de reproduzi-las pela imprensa, bem como por qualquer outro processo mecânico, direito que se estende aos herdeiros dos autores pelo tempo que a lei determinar".

Posteriormente foi publicada a primeira lei brasileira sobre direitos do autor, de $\mathrm{n}^{\mathrm{o}}$. 496 de 01 de agosto de 1898, onde definiu o instituto: "Os direitos de autor de qualquer obra literária, científica ou artística consistem na faculdade, que só ele tem, de reproduzir ou autorizar a reprodução do seu trabalho pela publicação, tradução, representação, execução ou de qualquer outro modo".

A constituição de 19 de novembro de 1937, cujo principal objetivo era a estruturação política do Estado brasileiro e omitiu-se totalmente de qualquer referência à propriedade imaterial. A preocupação era com a liberdade de expressão do pensamento, seja pela forma escrita, impressa ou através de imagens, instaurando no artigo 37, a censura: A censura prévia da imprensa, do teatro, do cinematógrafo, da radiodifusão, facultando à autoridade competente proibir a circulação, a difusão ou a representação. Já a Constituição de 18 de setembro de 1946 voltou a garantir o direito dos autores na reprodução das obras literárias, artísticas e científicas, no seu artigo $141^{2}$, parágrafo 19. Outra Constituição que garantiu o conteúdo da Constituição anterior foi a de 17 de outubro de 1967, em seu artigo $153^{3}$, parágrafo 25 .

A Constituição de 1988, por seu turno, consolidou a proteção dos direitos autorais ${ }^{4}$. $\mathrm{O}$ texto constitucional se refere à pessoalidade da autoria, no sentido de que o legislador

\footnotetext{
${ }^{2}$ Art. 141 - A Constituição assegura aos brasileiros e aos estrangeiros residentes no País a inviolabilidade dos direitos concernentes à vida, à liberdade, a segurança individual e à propriedade, nos termos seguintes:

$\S 19$ - Aos autores de obras literárias artísticas ou científicas pertence o direito exclusivo de reproduzi-las. Os herdeiros dos autores gozarão desse direito pelo tempo que a lei fixar (BRASIL, 1946).

${ }^{3}$ Art. 153. A Constituição assegura aos brasileiros e aos estrangeiros residentes no País a inviolabilidade dos direitos concernentes à vida, à liberdade, à segurança e à propriedade, nos termos seguintes:

$\S 25$. Aos autores de obras literárias, artísticas e científicas pertence o direito exclusivo de utilizá-las. Esse direito é transmissível por herança, pelo tempo que a lei fixar (BRASIL, 1967).

${ }^{4}$ Art. $5^{\circ}$ Todos são iguais perante alei, sem distinção de qualquer natureza, garantindo-se aos brasileiros e aos estrangeiros residentes no País a inviolabilidade do direito à vida, à liberdade, à igualdade, à segurança e à propriedade, nos termos seguintes:

XXVII - aos autores pertence o direito exclusivo de utilização, publicação ou reprodução de suas obras, transmissível aos herdeiros pelo tempo que a lei fixar;

XXVIII - são assegurados, nos termos da lei:

PIDCC, Aracaju/Se, Ano VIII, Volume 13 no 02, p.048 a 068 Jul/2019 | www.pidcc.com.br
} 
utiliza a expressão "autor" dando-lhe uma conotação pessoal, se referindo ao titular do direito autoral. Trata-se de exclusividade que, por influência da Convenção de Berna, reflete a necessidade da prévia autorização do criador da obra para possíveis utilizações desta publicamente.

A garantia individual da tutela é observada quando o legislador confere ao autor o direito exclusivo de utilização de sua obra. É um privilégio a ele concedido. Outra garantia prevista na Constituição é a da utilização pública, onde é garantida a percepção dos direitos patrimoniais nas formas de uso público de uma obra protegida, garantindo ao autor não somente direito ao exemplar único, mas a todas as cópias feitas a partir deste.

A transmissibilidade a termo da fruição é limitada no tempo aos herdeiros e sucessores do autor, pois a obra autoral tem um tempo de uso e gozo por parte do criador e herdeiros, após o qual se torna de domínio público.

\subsection{A Função dos Direitos Autorais}

Vive-se um período de transição paradigmática em que os chamados paradigmas emancipatórios tomam os lugares antes ocupados por ideários liberais e positivistas. A proteção da propriedade intelectual, seja no âmbito da propriedade industrial — marca; patente; desenho industrial; indicação geográfica; segredo industrial \& repressão à concorrência desleal —, seja no âmbito do direito autoral — direitos do autor; direitos conexos; e, programas de computador - , desde a sua concepção nos idos do Séc. XIX, por ocasião das convenções de Paris e Berna, respectivamente, sempre foi marcada por um viés eminentemente patrimonialista, personalíssimo, e, sobretudo, absoluto.

Leciona ASCENSÃO (2007, p.03) sobre a função dos Direitos Autorais, que esta se baseia em [...] "compensar o autor pelo contributo criativo trazido à sociedade. Por isso está aceito o ônus que representa a imposição do uso exclusivo". Todo direito autoral é assim acompanhado da consequência negativa de coactar a fluidez na comunicação social, fazendo surgir barreiras e multiplicando reivindicações.

A função social dos direitos autorais reconhece a necessidade da sociedade e flexibiliza os mesmos de modo a propiciar acesso aos menos favorecidos (CARBONI, 2008).

a) a proteção às participações individuais em obras coletivas e à reprodução da imagem e voz humanas, inclusive nas atividades desportivas;

b) o direito de fiscalização do aproveitamento econômico das obras que criarem ou de que participarem aos criadores, aos intérpretes e às respectivas representações sindicais e associativas .

PIDCC, Aracaju/Se, Ano VIII, Volume 13 no 02, p.048 a 068 Jul/2019 | www.pidcc.com.br 
Exemplo já consagrado de flexibilização à propriedade intelectual, no âmbito da propriedade industrial é, na forma do Decreto $n^{\circ}$ 6.108/2007, o licenciamento compulsório e, caso este não satisfaça os fins de sua criação, a importação paralela. Ocorre que no caso de um produto patenteado por empresa de fora do Brasil ser de primeira importância para o país, como é o caso de alguns remédios usados para o tratamento da AIDS, por exemplo, poderá o Brasil, caso os valores cobrados pela titular da patente sejam exorbitantes, quebrar a patente e licenciar empresas nacionais para a fabricação do medicamento ou importar paralelamente.

Aludida flexibilização não demonstra outra coisa senão os avanços que têm sido feitos no sentido de se garantir proteção ao interesse social. Ocorre, no entanto, que se é verdade que no campo da propriedade industrial, a exemplificação exposta representa verdadeira quebra de paradigmas, não é menos verdade que, no campo do Direito Autoral, as flexibilizações em nome do interesse social ainda têm sido vistas com muita desconfiança, dado o ainda grande poder de lobby dos detentores do poder comunicacional, especialmente as indústrias fonográfica e editorial, que, receosas de perderem margem de lucro em seus mercados, tentam, em hercúlea luta, brecar a socialização da cultura empreendida por meio da internet, por exemplo, exercendo influência junto aos políticos na luta contra a contrafação (pirataria).

Hoje, entende-se que os direitos do autor são um sistema sui generis e, no Brasil, estes compõem a esfera jurídica dos direitos civis.

\section{A PROPRIEDADE INTELECTUAL E A INTELIGÊNCIA ARTIFICIAL}

O fenômeno da internet que tem perturbado as indústrias fonográfica e editorial são programas compartilhadores de arquivos de torrent como kazaa, e-mule etc. Neles são partilhados os mais diversos tipos de arquivos, desde mídias musicais, livros, até pornografia. Aludidos programas se baseiam em redes peer-to-peer ou P2P. Peer, do inglês, quer dizer igual. São definidos como uma tecnologia utilizada para estabelecer uma espécie de rede de computadores virtual, no qual cada estação possui capacidades e responsabilidades equivalentes (O’BRIEN, 2006).

Existem as redes centralizadas, descentralizadas e mistas. Nas centralizadas, há um provedor central que detém arquivos a serem acessados por pessoas, no âmbito doméstico; já as descentralizadas se baseiam em difundir, os arquivos a serem partilhados, pela comunidade de computadores que formam a rede, fazendo com que cada usuário, do seu lar, seja participe 
igualmente responsável pela manutenção do sistema. As mistas utilizam-se de ambos os princípios; na verdade, o provedor central serve unicamente como buscador dos arquivos em cada computador da rede.

No Brasil, tanto as redes centralizadas, como as descentralizadas e as mistas não infringem qualquer normal de Direito Autoral. Diz o art. 46, inc. II, da LDA (lei $\mathrm{n}^{\circ}$ 9.610/1998), que "Não constitui ofensa aos direitos autorais: II - a reprodução, em um só exemplar de pequenos trechos, para uso do copista, desde que feita por este, sem intuito de lucro" (BRASIL, 1998). Ocorre que os arquivos baixados por meio destes programas são compartimentos, de tal sorte que o que se baixa são trechos que uma vez juntados no download formam o todo do arquivo; assim sendo, o caráter fragmentar do dispositivo em comento se faz cumprido. De mais a mais, os usuários deste tipo de software não têm intenção de amealhar lucro com seus arquivos baixados, os utilizados apenas em seus ipods, smartphones, tablets, pendrives, e computadores pessoais para uso próprio (O’BRIEN, 2006).

O primeiro país a descobrir e desenvolver a Internet foram os Estados Unidos na década de 80 (oitenta). Ulteriormente, com a globalização, outros países passaram a adotá-la, tais como: Inglaterra, Espanha, França, Alemanha, Itália, Portugal, União Européia e demais blocos.

No Brasil, a Internet surgiu em meados do ano de 1994, desenvolvendo-se no transcorrer dos anos. Dessa forma, com a evolução econômica, industrial, comercial, social e tecnológica, a Internet passou a fazer parte constante do cotidiano das relações dos indivíduos no Mundo atual (O’BRIEN, 2006).

Assim, a rede mais difundida e utilizada atualmente é a Internet. Criada em meados dos anos 60 , a rede que veio a transformar-se na Internet operava de forma descentralizada para oferecer comunicação e serviços aos usuários. Atualmente a Internet é utilizada no mundo inteiro, permitindo que seus usuários naveguem nas páginas da world, wide, web (www) para buscar informações, recursos multimídia e entretenimento. Outro serviço utilizado na rede é o de correio eletrônico (e-mail) permitindo o envio rápido e com custo reduzido de mensagens. Também é possível utilizar a Internet para bater papo (chat), assistir transmissões de áudio e vídeo, se divertir com os jogos on-line e ainda comprar e vender produtos e serviços (O’BRIEN, 2006).

As transferências de dados em alta velocidade tornaram possíveis aplicações que já haviam sido concebidas anteriormente, mas não funcionavam a contento devido a restrições tecnológicas de velocidade. A popularização das conexões à Internet por banda larga gerou 
uma série de impactos no uso da mesma, como as tecnologias de transmissão para áudio e vídeo, jogos on-line e no comércio eletrônico se popularizaram os produtos virtuais (CHOI; STAHL; WHINSTON, 1997).

No campo das criações intelectuais e artísticas, analisa-se que as trajetórias tecnológicas estão relacionadas à automatização do preparo e elaboração dos produtos; à velocidade dos processos produtivos; ao avanço na qualitativa da mão de obra; ao aumento da produtividade, às escalas ótimas de produção; ao controle dos fluxos; à melhoria da qualidade dos produtos envolvidos e das técnicas de criação. A introdução da internet no processo de criação, melhorias e armazenagem de obras intelectuais, por outro lado também facilitam a pirataria, vez que as informações ficam livres no sistema web.

O que ocorreu foi o surgimento da "Era da Informação", com o aparecimento de uma nova forma de máquina, dotada de inteligência artificial, tornando sistemas complexos de trabalho em funções simples (FELIPE; PERROTA, 2018). Assim, a inteligência artificial se apresenta como "tentativa inicial para replicar a cognição humana através de processos artificiais" (OLIVEIRA, 2017, p. 3).

A inteligência artificial não pode ter uma única definição, por conta de sua complexidade. Gabriel (2018, p. 185) diz que ela é "a área da Ciência da Computação que lida com o desenvolvimento de máquinas/computadores com capacidade de imitar a inteligência humana". Russel; Norvig $(2009)^{5}$ ensinam que esta tríade: máquina/imitação/inteligência humana abrange habilidades como: raciocínio, conhecimento, criatividade, solução de problemas complexos, percepção, aprendizagem, planejamento, habilidade de manipular e mover objetos, dentre outras.

Pensar sobre propriedade intelectual, inteligência artificial, machine learning e robôs criativos se tornou desafio, o que ainda não foi regulado no direito brasileiro, uma vez que o homem, autor do código original, não detém o controle sobre as ações e as produções da inteligência artificial. Portanto, como definir quem possui a propriedade intelectual dos resultados da IA?

De um lado, correntes militam que inserir criações da Inteligência Artificial ao domínio público reduziria o incentivo ao desenvolvimento de novas tecnologias no campo artístico. Por outro lado, existem correntes que defendem que o controle da criatividade da IA é indeterminado, na medida em que as ações espontâneas da tecnologia durante a criação de

\footnotetext{
${ }^{5}$ Tradução do vernáculo inglês para o português realizada por esta articulista. PIDCC, Aracaju/Se, Ano VIII, Volume 13 no 02, p.048 a 068 Jul/2019 | www.pidcc.com.br
} 
uma obra podem ser observadas, fazendo com que a criação não pudesse ser protegida de forma privada.

Contudo, no Brasil de acordo com a Lei de Direitos Autorais, em seu art. $11^{\mathrm{o}}$ (BRASIL, 1998): "autor é a pessoa física criadora da obra." Assim, segundo a Lei, uma obra criada por uma máquina já nasceria em Domínio Público.

A infovia ${ }^{6}$ pública está inserida nessas camadas como a rede de baixo custo que permite o acesso universal de pessoas e equipamentos. Através dela é que estão estruturados os serviços genéricos de comércio eletrônico que estão disponíveis para empresas e clientes. Transferências de arquivos, salas virtuais e software de criptografia são alguns destes serviços e aplicações.

Segundo Choi; Stahl; Whinston (1997, p. 24) "a maioria das criações intelectuais, bens intangíveis, pode ser encarada como um produto virtual; software, fotos, vídeo, música, livros, mapas, conteúdos educacionais e textos, já que todos esses conteúdos podem ser digitalizados" e "transmitidos pela Internet dos produtores aos clientes. Nos clientes, os produtos virtuais poderão ser utilizados na própria interface de acesso à Internet ou transferidos para outros suportes como o papel”, no caso "dos livros, mapas e textos, ou dispositivos digitais móveis, como os players de áudio, celulares e PDA" (CHOI; STAHL; WHINSTON, 1997).

Portanto, o chamado comércio eletrônico é uma apresentação eletrônica de bens e serviços, recebimento de pedidos via internet, faturamento, pagamento e gerenciamento de transações. Mais que isso, ajuda a gerar uma procura de produtos e serviços, melhorando a comunicação, gerenciamento, pagamento e ajudando a empresa a descobrir novos mercados. Com o comércio eletrônico as empresas podem aumentar sua margem de lucro usando canal on-line, reduzindo custos associados a processos de papéis: impressão, manuseio e postagem, fornecendo aos clientes serviços rápidos e melhores, pois esse serviço é destinado às pessoas que procuram mais facilidade, rapidez e eficiência nos processos de compra e venda de bens.

Cada Nação tem suas próprias leis sobre Direitos Autorais, naturalmente circunscritas aos atos cometidos em seu território, com jurisdição sobre as pessoas nele habitando, em consequência, incapazes de fornecer proteção, em termos da matéria, aos seus cidadãos em território estrangeiro.

No Brasil é a Lei 5.988, de 14 de dezembro de 1973, retificada em 09 de dezembro de 1974, que regula os Direitos Autorais. Embora já se tenha observado que há um tempo

\footnotetext{
${ }^{6}$ Conceito comumente difundido na área digital como o conjunto de linhas digitais por onde trafegam os dados das redes eletrônicas.

PIDCC, Aracaju/Se, Ano VIII, Volume 13 no 02, p.048 a 068 Jul/2019 | www.pidcc.com.br
} 
considerável, a questão dos Direitos Autorais extravasou fronteiras nacionais, onde o estabelecimento de consenso entre Países que desejam assegurar a proteção internacional da propriedade intelectual de seus cidadãos é fato historicamente recente, tendo desabrochado num campo do Direito Internacional ainda pouco explorado.

Trata-se, hoje em dia, de repetir o óbvio, quando se diz que a evolução meteórica da Internet, passando de rede universitária e governamental a plataforma de comunicações e trocas diversificadíssimas, vem revolucionando continuada e dinamicamente variados setores econômicos, tendo já adquirido enorme relevância nos domínios culturais, educativos e sociais, oferecendo a cidadãos e educadores mecanismos que facilitam o processo criativo, a difusão de seu conteúdo, e, igualmente, oferecendo oportunidades de acesso universal a fontes de informações as mais diversificadas. Por conseguinte, a pirataria é um problema crítico da internet. Inúmeros livros, filmes, séries de TV, músicas, CDs e DVDs inteiros são objeto de inúmeras transferências gratuitas por usuários de todo o mundo.

Em primeiro lugar, é preciso identificar qual o aspecto oferece as melhores condições para uma intervenção que busque mudar o comportamento dos consumidores. Não é muito difícil perceber que esse aspecto certamente é a noção generalizada de que a pirataria traz prejuízos à atração de investimentos e à geração de empregos. Uma ação que intente reverter a situação atual, deverá, certamente, enfatizar essa noção já amplamente aceita pelos consumidores.

Por outro lado, se deve identificar quais aspectos dificultam a intervenção. Um deles é a curiosa sensação de que a restrição orçamentária justifica a aquisição de produtos piratas. Isso é verificado quando os consumidores entrevistados afirmam que só consomem produtos piratas quando não têm condições financeiras para comprar o original, o que levaria a crer que esse consumo ocorre acompanhado de algum sentimento de culpa. Mas não é o que de fato ocorre. O consumo de produtos piratas acontece sem o sentimento de culpa e, mais que isso, não constrange o consumidor o fato de outras pessoas saberem que ele comprou um produto pirata.

Dessa segunda observação é possível identificar outro ponto de intervenção. Qual seja: a intenção de consumir produtos originais, caso as suas condições financeiras permitissem. Porém, uma barreira dificulta esse hábito: a sensação de que a falta de recursos financeiros justifica e torna "limpo" o consumo de produtos piratas. Logo, qualquer campanha de mudança de comportamento deve fazer com que o consumidor se sinta "sujo" ao comprar um produto pirata, mesmo que não tenha condições de comprar o original. Isso gera dois 
benefícios imediatos: $1^{\circ}$ ) o consumidor deixará de consumir produtos piratas pela óbvia sensação de que se trata de um mercado ilegal e; $2^{\circ}$ ) ainda que as condições financeiras de fato o limitem, a própria noção de errado e o constrangimento perante a sociedade o farão resistir ao consumo do produto pirata.

Entretanto, se se deseja obter resultados, precisa-se de elementos que provoquem o maior impacto possível. Talvez sensibilize as pessoas saber que os bilhões estimados em impostos que deixam de ser arrecadados no Brasil, causam danos sociais irreparáveis; Talvez por meio do próprio Código Penal, com a criminalização do direito de autor, também seja um elemento útil.

É preciso lembrar que quando foi inventada a imprensa, os soberanos ficaram preocupados devido à iminente democratização da informação, com isso criaram um instrumento de censura que consistia em dar aos donos dos meios de produção dos livros o poder de comercializar os títulos que editassem, uma vez que estes controlariam o conteúdo para que não fossem contrários à vontade do Estado.

Esse privilégio no controle dos livros foi chamado de copyright (direito de cópia), que surgiu de um direito dos livreiros para garantir o seu poder de reproduzir as obras, e não como um direito dos autores dos livros. (VIANNA, 2005).

Apenas ao proprietário cabe o direito de doar, trocar ou vender a coisa, pois se assim o fizer perderá os direitos de dela usar e fruir. Mas um autor, não perde nada com a cópia de sua obra, porque assim mais pessoas lerão os seus livros, ouvirão suas músicas e apreciarão sua arte, tornando-se assim mais reconhecido pela sociedade.

Atualmente, ficam claras as razões dessa distinção fundamental entre a natureza da propriedade material e a da propriedade intelectual, especialmente quando, no plano jurídico dos "direitos de personalidade", se diz que os direitos morais de autor de obras intelectuais são intransmissíveis e irrenunciáveis.

Destarte, por mais que o "trabalho intelectual" tenha um grande "valor de uso" em uma sociedade, o "valor de troca" dele estará ligado à venda de produtos, como o papel, e serviços, como a cópia manual ou impressa. Se uma idéia é reproduzida oralmente, não tem qualquer "valor de troca", mesmo que tenha um grande "valor de uso", porque pode ser reproduzida diversas vezes. Ou seja, o "valor de troca" de um bem específico está ligado à sua disponibilidade no mercado.

Com esse novo processo de distribuição do trabalho intelectual, o custo dos bens e serviços para se obter uma obra se tornou praticamente zero. Consequentemente, o "valor de 
troca" do trabalho intelectual que era ligado à falta de disponibilidade deste na sociedade, não pôde mais ser mantido. Assim, no livre mercado, o "valor de troca" do trabalho intelectual é zero, porque podem ser reproduzidas infinitas vezes e existe em grande quantidade no mercado.

Mesmo com a digitalização das obras, elas continuam sendo reproduzidas fisicamente pelas editoras, gravadoras e produtoras. Apesar das pessoas encontrarem livros, músicas e filmes facilmente através da internet, estes continuam sendo vendidos pelo mundo todo, porque ainda existem pessoas interessadas em comprá-los. De tal modo, continua o mesmo esquema de alienação pelos autores do "trabalho intelectual" aos proprietários dos meios de produção: os primeiros recebem a remuneração pela realização de seu trabalho e os segundos o lucro que investiram.

$\mathrm{Na}$ sociedade capitalista digital, o trabalho intelectual enquanto inédito tem "valor de troca", ou seja, se um capitalista tem uma idéia pioneira é garantido um tempo de vantagem em relação a seus concorrentes. Com a compra do "trabalho intelectual" inédito pelos produtores garante-se os lucros resultantes do pioneirismo de sua exploração. Com esse acontecimento é notável que, com as invenções da indústria tecnológica sendo comercializadas, rapidamente serão copiadas pelos seus concorrentes. Outrossim, o que garante os lucros das empresas são principalmente o segredo industrial e o pioneirismo. (VIANNA, 2005).

A recente dinâmica da economia e das tecnologias reforçou a aparente inconsistência do termo "propriedade intelectual". Como a relação não só de constituição do bem (criação intelectual), mas também de sua transferência a terceiros sofre diferenças fundamentais do regime adotado para a propriedade convencional. Ao invés do termo "propriedade intelectual", a doutrina no Brasil prefere o uso da expressão "direito de autor" ou "direito autoral" (terminologia adotada pela legislação civil e penal brasileira). Sendo assim, a denominação "propriedade" é deixada para os direitos e privilégios no campo das patentes de invenção, modelos de utilidades ou industriais e marcas de serviço, indústria ou comércio ("propriedade industrial").

A Constituição Federal, em seu artigo $5^{\circ}$, inciso XXVII, estabelece como direito inviolável e exclusivo dos autores a utilização, publicação ou reprodução de suas obras, transmissível aos herdeiros pelo tempo que a lei fixar. Em seguida, a Lei 9.610/98 consolida as legislações sobre o direito autoral. Para compreender o estado da arte no Brasil, é de grande valia atentar-se para alguns trechos, em especial, da lei. Uma distinção fundamental feita pelo 
dispositivo legal diz respeito aos direitos morais e aos direitos patrimoniais de autor. Referida lei apresenta os direitos morais de autor, que, vale destacar, aludem aos direitos de personalidade, conforme segue:

O direito industrial, a seu turno, resguarda quatro bens imateriais, são eles: a) A patente de invenção; b) A patente de modelo de utilidade; c) O registro de desenho industrial; d) $\mathrm{O}$ registro de marca.

O direito de explorar economicamente esses elementos (patente ou registro) é do empresário titular desses bens, direito que lhe é assegurado com inteira exclusividade. Se o empresário registra sua marca pode impedir que a concorrência utilize a mesma marca ou de alguma parecida. Contudo, há possibilidade de que outra pessoa possa vir a explorar o bem industrial patenteado ou registrado (invenção, modelo, desenho ou marca), mas, ela necessita de autorização ou licença do titular do bem. Assim como os demais bens integrantes do patrimônio do empresário, as patentes e os registros podem perfeitamente ser alienados por ato inter vivos ou mortis causa. (COELHO, 2015).

Observa-se que, "Ninguém pode reivindicar o direito de exploração econômica com exclusividade de qualquer invenção, modelo de utilidade, desenho industrial ou marca se não obtiver do INPI a correspondente concessão". (COELHO, 2015). Para que o empresário tenha direito de exploração exclusiva da marca e do desenho industrial é necessário que os registre no INPI. O direito brasileiro conferiu ao registro industrial o caráter de ato administrativo constitutivo. Ou seja, o direito de utilização exclusiva do desenho ou da marca não surgiu da anterioridade em sua utilização, mas da anterioridade do registro.

Para que o registro do desenho industrial possa ser concedido ele deve atender a alguns requisitos dispostos na LPI, como: a) Novidade - a lei estabelece que o objeto do desenho industrial deve ser novo, isto é, não compreendido no estado da técnica. O projeto feito pelo desenhista deve, para requerer a proteção do direito industrial, proporcionar um resultado visual inédito, desconhecido dos técnicos da área; b) Originalidade - pode-se dizer que para ser original o desenho industrial precisa apresentar uma configuração própria, não encontrada em outros objetos, ou quando combina com originalidade elementos já conhecidos. Enquanto a novidade é uma questão técnica, a originalidade é estética e são consideradas categorias distintas, muitas vezes confundidas na propriedade intelectual; c) Desimpedimento - há casos em que a lei impede o registro de desenho industrial. São exemplos de impedimento: desenhos contrários à moral e aos bons costumes, ofensivos a 
honra ou a imagem de pessoas ou atentatórios à liberdade de consciência; formas comuns, vulgares ou necessárias (ARRABAL, 2018).

Quanto ao prazo, a lei estabelece duração de 10 anos para o registro de desenho industrial, que serão computados da data do depósito, e podem ter prorrogável por até 3 períodos sucessivos de 5 anos cada.

Como existem vários produtos com um mesmo gênero se fez necessário a utilização de algum sinal para diferenciá-los e este fato deu origem a marca. A marca, que tem duração de 10 anos, a partir de sua concessão e é prorrogável por períodos iguais e sucessivos, para ser registrada também tem que atender alguns requisitos dispostos na LPI, sem os quais não será possível o seu registro, são eles: a) Novidade relativa - a lei não determina que a marca precisa ser uma novidade absoluta, ou seja, a expressão linguística ou signo utilizado não precisam ser, criados pelo empresário. O que deve ser nova é a utilização daquele signo na identificação de produtos industrializados ou comercializados, ou de serviços prestados. Por isso, a marca é protegida, em princípio, apenas no conjunto de atividades econômicas afins; b) Não colidência com marca notória - O Brasil é signatário da Convenção de Paris, em razão disto, as marcas notoriamente conhecidas têm a tutela do desenho industrial, mesmo que não registradas no INPI; c) Não impedimento - determina que para ser registrado como marca, não pode o signo correspondente enquadrar-se nos impedimentos legais. É expressamente proibido o registro, como marca, de determinados signos. Por exemplo, as armas oficiais do estado, o nome civil, salvo autorização pelo seu titular, etc. (COELHO, 2015).

O INPI, autarquia responsável pelo registro da marca, distingue as muitas atividades econômicas da indústria, comércio e serviços, agrupando-as conforme o critério de afinidade. Exemplificando: Empresas têxteis, alimentícias, prestadoras de determinados serviços, etc. Sendo assim, será concedida proteção à marca dentro de sua classe. Se surgir no mercado uma marca igual ou mesmo semelhante, porém, em atividade enquadrada fora da sua classe, não poderá o empresário opor-se. O titular do registro de uma marca terá direito à sua exploração exclusiva nos limites fixados por esta classificação.

A lei dispõe de uma exceção neste caso, o titular de marca de alto renome terá o direito de exploração total da marca, ficando vedado a outros empresários a usurparem, não importando a que classe pertença seu produto ou serviço. O registro de determinada marca na categoria das de alto renome é ato discricionário do INPI, insuscetível de revisão pelo poder judiciário, senão quanto a seus aspectos formais. 
A taxa devida ao INPI para eficácia do registro de marca é conhecida como retribuição e é devida na concessão e a cada prorrogação do registro. O registro de marca caduca, salvo força maior, se sua exploração econômica não se iniciar no Brasil em 5 anos, a partir da sua concessão, no caso da interrupção desta exploração ocorrer por período de 5 anos consecutivos, ou na de alteração substancial da marca.

\title{
3.1. A Patentiabilidade
}

A Organização Mundial da Propriedade (OMPI), a partir de 1967, foi constituída como órgão autônomo dentro do sistema das Nações Unidas, englobando as Uniões de Paris e de Berna, além de perfazer uma articulação com a recente União para a Proteção das Obtenções Vegetais, e a administração de uma série de outros tratados.

Para a Convenção da OMPI, a Propriedade intelectual consiste na soma dos direitos relativos às obras literárias, artísticas e científicas, às interpretações dos artistas intérpretes e às execuções dos artistas executantes, aos fonogramas e às emissões de radiodifusão, às invenções em todos os domínios da atividade humana, às descobertas científicas, aos desenhos e modelos industriais, às marcas industriais, comerciais e de serviço, bem como às firmas comerciais e denominações comerciais, à proteção contra a concorrência desleal e todos os outros direitos inerentes à atividade intelectual nos domínios industrial, científico, literário e artístico.

Devido ao implemento da informática, as ações comerciais se dinamizaram, em consequência, surgiram novas conjunturas a serem mediadas pelo direito. O registro de nome de domínio na internet, por exemplo, se tornou um campo fértil para a usurpação de marcas.

Conforme Coelho (2015, p.92):

\begin{abstract}
A solução para tal fato se deu com a adoção do critério da anterioridade do registro da marca no INPI e não da anterioridade de solicitação do nome de domínio. Pois, obviamente, se o indivíduo já era o titular do registro, terá também o direito de poder usufruir da marca para o nome de domínio. Assim, o legítimo titular de marca registrada tem o direito de reivindicar o endereço eletrônico concedido pela FAPESP a outra pessoa, sempre que o domínio reproduzir sua marca. A ordem de chegada só prevalecerá se os dois interessados possuírem (cada um, uma classe diferente) o registro da marca adotada no nome de domínio.
\end{abstract}

A patente corresponde a um título de propriedade temporária sobre uma invenção ou modelo de utilidade, outorgados pelo Estado aos inventores ou autores ou outras pessoas 
físicas ou jurídicas detentoras de direitos sobre a criação. De outra forma, o inventor se obriga a demonstrar detalhadamente todo o conteúdo técnico da matéria assegurada pela patente. No decorrer do prazo de vigência da patente, o titular tem o direito de excluir terceiros, sem sua prévia autorização, de atos relativos à matéria protegida, tais como fabricação, comercialização, importação, uso, venda, etc.

Para Marinho (2011, p. 80) "o título de patentes tem se consolidado como uma propriedade voltada para o mercado, cujo escopo é definido pelo equilíbrio entre acesso e incentivo à produção de inovação". Ademais, a invenção é dotada de atividade inventiva sempre que, para um técnico no assunto, não decorram de maneira evidente ou óbvia do estado da técnica.

Pode-se considerar como invenção qualquer obra original do gênio humano. Se uma pessoa consegue projetar ou melhorar algo e o faz de forma inédita, terá desenvolvido uma invenção. E a novidade é a condição de privilegiabilidade da invenção (COELHO, 2015).

Ainda para Coelho (2015, p.86):

\begin{abstract}
Assim como a invenção, o modelo de utilidade não pode decorrer de maneira óbvia do estado de técnica, claro que segundo o julgamento de um especialista na matéria. E também terá que ser objeto de uso prático suscetível de aplicação industrial, com novo formato de que resulta em melhores condições de uso ou fabricação. Não há propriamente invenção, mas aumento na utilidade de alguma ferramenta, instrumento de trabalho ou utensílio, pela ação da novidade parcial que lhe agrega. Pode ser chamada, também, de "pequena invenção" e goza de proteção autônoma em relação à invenção cuja utilidade foi melhorada.
\end{abstract}

À semelhança da marca, a patentiabilidade de invenções e modelos de utilidade está sujeita aos requisitos determinados pela lei de propriedade industrial, são quatro: a) Novidade - entende-se que é tudo aquilo que não se encontra compreendido no estado da técnica, o que abrange tudo que não tiver sido divulgado por escrito ou oralmente, até a data do depósito do pedido de patente de invenção. Não basta, para obtenção do direito industrial, que a invenção ou o modelo sejam originais, características de natureza subjetiva (isto é, relacionada ao sujeito criador). É preciso que a criação seja desconhecida pela comunidade científica, técnica ou industrial; b) Atividade inventiva - consiste em uma atividade de criação, na esfera técnica, por parte do inventor. c) Aplicação industrial - atualidade prática da invenção. Somente a invenção ou modelo suscetível de aproveitamento industrial pode ser patenteado; d) Não impedimento - a lei veda, por motivos de ordem técnica ou atendimento ao interesse público, a patentiabilidade de determinadas invenções ou modelos (COELHO, 2015). 
Existem criações que não podem ser enquadradas como invenções, nem como modelo de utilidade. A título de exemplos, as descobertas, as teorias científicas e os métodos matemáticos; as concepções puramente abstratas; os esquemas, os planos, os princípios ou os métodos comerciais, contábeis, financeiros, educativos, publicitários, de sorteio e de fiscalização; as obras literárias, arquitetônicas, artísticas e científicas ou qualquer criação estética; programas de computador em si; apresentação de informações; regras de jogos, técnicas e métodos operários ou cirúrgicos, bem como métodos terapêuticos ou de diagnóstico, de aplicação no corpo humano ou animal (COELHO, 2015).

Os licenciados terão que explorar a invenção ou o modelo de utilidade dentro de um prazo. Outorgada a primeira licença compulsória, segundo a lei, existe o prazo de 2 anos para que a exploração econômica da invenção ou do modelo de utilidade seja executada. Após tal prazo, mediante a permanência da situação irregular, objeto do licenciamento obrigatório, realiza-se a caducidade da patente. Assim, o inventor perde todos os direitos industriais que titularizava, e a invenção ou modelo cai em domínio público (COELHO, 2015).

Além do término do prazo de duração e da caducidade, existem outros casos de extinção da patente, segundo Coelho (2015): a) A renúncia aos direitos industriais, que apenas ocorrerá se não houver prejuízo para terceiros (licenciados, por exemplo); b) Falta de pagamento da taxa devida ao INPI, conhecida como "retribuição anual"; c) A falta de representante no Brasil, quando o titular é domiciliado no exterior.

No que concernem às licenças, são elas: a) Licença voluntária - na qual o titular de patente ou o depositante pode firmar contrato de licença para exploração, podendo, ainda, este conceder todos os poderes ao licenciado para agir em defesa da patente e, caso haja aperfeiçoamento em patente licenciada, este pertencerá a quem o fez, sendo garantido à outra parte contratante o direito de preferência para o seu licenciamento; b) Oferta de licença - no qual o titular da patente pode requerer junto ao INPI que a coloque em oferta com fins de exploração. Ao titular da patente cabe requerer o cancelamento da licença tanto se o licenciado não iniciar a exploração efetiva dentro do prazo de um ano da concessão ou se interromper a exploração por tempo superior a um ano ou, ainda, se não forem cumpridas as condições da exploração; c) Da licença compulsória - esta última consiste em submeter a ter a patente licenciada de forma compulsória, o titular que exercer seus direitos de forma abusiva, ou através dela praticar abusos de poder econômico, que sejam comprovados nos termos da lei, por decisão administrativa ou judicial, bem como a não exploração do objeto da patente no território brasileiro por falta de fabricação ou fabricação incompleta do produto, ou, ainda, 
a falta de uso integral do processo patenteado, ressalvados os casos de inviolabilidade econômica, quando será admitida a importação ou pela comercialização que não satisfizer às necessidades do mercado.

\section{CONCLUSÃO}

A aceleração do processo evolutivo e o desenvolvimento das tecnologias passaram a exigir a criação de uma nova categoria de direitos de propriedade. A propriedade intelectual refere-se a estes direitos e visa garantir a exclusividade e assegurar a reprodução das criações intelectuais.

Para que haja um maior controle sobre as criações intelectuais, primeiro é fundamental que haja maior rigidez na aplicação das leis já existentes. Em segundo, é importante que se tenha um maior controle sobre todos os aspectos resguardados por elas, pois ter uma segurança maior em relação ao seu trabalho é um fator importante para os que dependem do correto funcionamento da legislação. Pode-se aferir que os direitos à Propriedade Intelectual são fundamentais para garantir aos autores uma maior proteção sobre suas criações, pois é através das leis elaboradas para esse fim que eles podem encontrar bases jurídicas sólidas o suficiente para assegurar o direito sobre o conhecimento, sendo este publicado ou não.

À guisa de uma conclusão, é pertinente realçar que os direitos autorais são espécie da qual a propriedade imaterial é gênero. Historicamente, os direitos autorais são decorrentes de duas vertentes distintas: tecnológica e ideológica. A primeira vertente, pautada no surgimento do maquinário que possibilitou as reproduções em série de textos, de obras plásticas ou de audiovisuais. Já a segunda, inspirada nos princípios individualistas que impulsionaram a Revolução Francesa, atingiram o seu ápice com a globalização da economia.

Observa-se, afinal, que os direitos autorais podem ser entendidos como um instituto composto por uma dualidade de interesses. De um lado, os interesses privados, baseados no exercício da liberdade de expressão e no desejo do autor de ser recompensado, de algum modo, por sua criação intelectual. Do outro lado, os interesses públicos, o direito à informação, na medida em que a continuidade da criação intelectual contribui para o aumento do patrimônio cultural desfrutado por toda a coletividade. Assim, a finalidade do direito autoral não se limita a estimular a criação, devendo existir um equilíbrio entre interesses privados e públicos, de modo que seja resguardado o princípio da função social dessa 
categoria de direitos. A função social do direito autoral sustenta-se no direito coletivo de acesso ao conhecimento e à informação, sendo estes direitos fundamentais previstos na Constituição Federal.

Cabe questionar, porém, o novo embasamento da propriedade intelectual face a era digital. Assim, a Lei de Direitos Autorais estabelece que uma obra criada por uma máquina já nasceria de Domínio Público, o que requer a necessidade de maior rigidez e atualização das leis, não só em cada país, mas com certeza, em acordos firmados entre eles, mormente quanto a tecnologias decorrentes da inteligência artificial, cada vez mais necessária e utilizada pela sociedade globalizada.

\section{REFERÊNCIAS}

ABRÃO, Eliane Yachouch. Direitos de Autor e Direitos Conexos. $2^{\mathrm{a}}$ ed. São Paulo: Migalhas, 2014.

ARRABAL, Alejandro Knaesel. Propriedade intelectual e inovação: observações a partir da complexidade. NOMOS - Revista do Programa de Pós-graduação em Direito - UFC, v. 38, n. 2, 2018. Disponível em: http://www.periodicos.ufc.br/nomos/article/view/20338/95962.

Acesso em: 27 jun. 2019.

ASCENSÃO, José de Oliveira. Direito autoral. 2a Ed. Rio de Janeiro-RJ: Ed. Renovar. 2007.

BARBOSA, Denis Borges. Tratado da propriedade intelectual. 2 ed. Rio de Janeiro: Lumen Juris, 2017. Tomo 1.

BARROS, Carla Eugenia Caldas. Manual de Direito da Propriedade Intelectual, Evocati: Aracaju, 2007.

BITTAR, Carlos Alberto. Direito do autor. 7 ed. Rio de Janeiro: Forense, 2019.

BRASIL. Constituição (1946). Constituição dos Estados Unidos do Brasil (de 18 de setembro de 1946). Disponível em: http://www.planalto.gov.br/ccivil_03/constituicao/constituicao46.htm. Acesso em: 07 set. 2017.

Constituição (1967). Constituição da República Federativa do Brasil de 1967. Disponível em: http://www.planalto.gov.br/ccivil_03/constituicao/constituicao67.htm. Acesso em: 07 set. 2017.

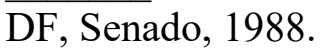


Lei $n^{0}$ 9.610, de 19 de fevereiro de 1998. Altera, atualiza e consolida a legislação sobre direitos autorais e dá outras providências. Disponível em: http://www.planalto.gov.br/ccivil_03/leis/19610.htm. Acesso em: 20 out. 2018.

Lei $\mathbf{n}^{0}$ 9.609, de 19 de fevereiro de 1998. Dispõe sobre a proteção da propriedade intelectual de programa de computador, sua comercialização no País, e dá outras providências. Disponível em: http://www.planalto.gov.br/ccivil_03/leis/19609.htm. Acesso em: 20 out. 2018.

CARBONI, Guilherme. Função social do direito de autor. Curitiba: Juruá, 2008.

CHOI, Soon-Yong; STAHL, Dale; WHINSTON, Andrew. The Economics of Electronic Commerce. Indianápolis: McMillan Technical Publishing, 1997.

COELHO, Fábio Ulhoa. Manual de Direito comercial: direito de empresa. - 27. Ed. - São Paulo: Saraiva, 2015.

FELIPE, Bruno Farage da Costa; PERROTA, Raquel Pinto Coelho. Inteligência Artificial no Direito: uma realidade a ser desbravada. Revista de Direito, Governança e Novas Tecnologias. v. 4, n. 1. p. 01-16, jan/jun. 2018).

GABRIEL, Martha. Você, eu e os robôs: pequeno manual do mundo digital. São Paulo: Atlas, 2018.

MARINHO, Maria Edelvary P. As justificativas comuns para o direito de patentes. Nomos, $\quad$ v. $31, \quad$ n. $2, \quad 2011 . \quad$ Disponível em: http://www.periodicos.ufc.br/nomos/article/view/387/ Acesso em: 27 jun. 2019.

O'BRIEN, James A. Sistemas de Informação e as decisões gerenciais na era da Internet. 2 ed. São Paulo: Saraiva, 2006.

OLIVEIRA, Anna Flávia Aguilar Santos de. Inteligência Artificial e Personalidade: Agência, Imputação e Responsabilidade. Faculdade de Direito da Universidade Federal de Juiz de Fora (UFJF), 2017. Disponível em: http://www.egov.ufsc.br/portal/sites/default/files/inteligencia_artificial_e_personalidade_agen cia.pdf. Acesso em: 27 jun. 2019.

RUSSEL, S.; NORVIG, P. Artificial Intelligence: a modern approach.3rd ed. London; Pearson, 2009.

VIANNA, Túlio Lima. A ideologia da propriedade intelectual: a inconstitucionalidade da tutela penal dos direitos patrimoniais de autor. Revista da Escola da Magistratura do Estado do Rio de Janeiro, v. 30, p. 89-108. Rio de Janeiro: 2005. Disponível em: http://jus2.uol.com.br/doutrina/texto.asp?id=8932. Acesso em: 26 jun. 2019. 